\title{
A Preventative Approach to Oral Health for Children in a Regional/Rural Community in South-West Victoria, Australia
}

\author{
Ashlinn Mason, Lara Mayze, Jacqui Pawlak, Margaret J Henry, Sharon Sharp and Michael C Smith*
}

Barwon Health, Oral Health Services, 104-108 Bellarine Highway, Newcomb 3219, Victoria, Australia

\begin{abstract}
Dental caries is a major health problem in most industrialised countries. Childhood dental disease can cause acute pain, difficulty eating resulting in reduced self-esteem and sleep deprivation. The treatment of oral disease using traditional methods is costly and in industrialized countries currently rates the fourth most expensive disease to treat. Dental professionals are currently facing an unfathomable task of how to manage the large burden of consequences associated with caries progression across the world.
\end{abstract}

The Barwon South-West Region of Victoria, Australia is a diverse regional/rural area. Some communities are quite remote. Barwon Health and Colac Area Health Oral Health Services developed an outreach program to improve access to dental services for children. A Minimal Intervention Dentistry approach was incorporated and includes early diagnosis, risk assessment, early detection of mineral loss, non-surgical treatment and preservation of the tooth structure.

Kindergartens throughout the region and children in the first year of Primary School are visited by Oral Health Therapists. Teeth are scored according to the International Caries Detection Assessment System and any early 'white spot' lesions identified have fluoride varnish applied. Children receive up to three dental check-ups during the year and given a toothbrush and toothpaste at each visit. Parent engagement sessions are conducted during Visit 2.

Examinations and fluoride application take only $3-6$ minutes for each child, compared with the usual 30 minute appointments in dental clinics. Two virtual chairs have been created as two dental teams visit Kindergartens throughout the Barwon Region, significantly easing pressure at Community dental clinics. The Kinder Wide Smiles program successfully intervened in the oral health of 5,305 children in the region. Most importantly, one of the barriers for children not presenting to static dental clinics for screening has been eliminated.

Keywords: Dental; Paediatric; Service innovation; Oral health; Regional/Rural

\section{Background}

Oral diseases are thought to affect 3.9 billion people globally and untreated caries in permanent teeth, with decay due to mineral loss, is the most common condition reported [1]. Dental caries is a major health problem in most industrialised countries and is thought to affect $60-90 \%$ of school aged children [2]. A report from the Australian Institute of Health and Welfare observed that $40 \%$ of $4-5$ year old children within Australia experienced caries [3]. Childhood dental disease can cause acute pain, difficulty eating resulting in reduced self-esteem and sleep deprivation. Severe childhood caries can have consequences for the carer with time away from work and general disturbance to normal family life [4]. Studies have observed that in children from low socioeconomic areas, caries commonly co-exist $[5,6]$ and with obesity [5].

The treatment of oral disease using traditional methods is costly and in industrialized countries currently rates the fourth most expensive disease to treat [2]. Within Australia, poor oral health has a significant economic cost and in 2011-2012 total expenditure on dental services was $\$ 8,336$ million [7]. This current study examines the regional and rural areas of Geelong and the Colac-Otway Shire (South-West Victoria, Australia) and includes disadvantaged sectors of the communities where many children have required emergency dental procedures (1,085 visits in children aged $0-12$ yr for 2014) due to gross caries. Parents have been observed to present at dental services when the child was experiencing pain, not for regular dental checkups. While some children receive dental treatment within the dental chair, for more severe cases a dental general anaesthetic (GA) may be required [8]. Dental GA's use intensive resources and patients may experience side-effects or complications [9].
Minimal Intervention Dentistry (MID) is a practice that attempts to ensure that teeth are kept functional for life [10]. MID includes early diagnosis, risk assessment, early detection of mineral loss, non-surgical treatment and preservation of the tooth structure [11,12]. A study in the Northern Territory with indigenous children utilised a MID approach of applying concentrated topical fluoride to an intervention group over a two year period [13]. The efficacy of the intervention was examined utilising the net dental caries increment and was lower in the intervention group compared to the control group by an average of 3.0 surfaces per child.

Dental professionals are currently facing an unfathomable task of how to manage the large burden of consequences associated with caries progression across the world. Population health promotion and prevention strategies aimed at younger children can potentially improve oral health throughout adult life. 'Smiles4Miles' is a Dental Health Services Victoria (DHSV) initiative which began in 2004 and works in partnership with Community Dental Health Clinics to improve the oral health of pre-school aged children in Victoria. The key health promotion messages encouraged with the 'Smiles4Miles' program focussed on Eat Well, Drink Well, Clean Well, Play Well

*Corresponding author: Dr Michael Smith, Barwon Health, Oral Health Services, 104-108 Bellarine Highway, Newcomb 3219, Victoria, Australia, Tel: 610409 014953; E-mail: michae@barwonhealth.org.au

Received June 01, 2015; Accepted June 15, 2015; Published June 25, 2015

Citation: Mason A, Mayze L, Pawlak J, Henry MJ, Sharp S, et al. (2015) A Preventative Approach to Oral Health for Children in a Regional/Rural Community in South-West Victoria, Australia. Dentistry 5: 313. doi:10.4172/2161-1122.1000313

Copyright: ( 2015 Mason A, et al. This is an open-access article distributed under the terms of the Creative Commons Attribution License, which permits unrestricted use, distribution, and reproduction in any medium, provided the original author and source are credited. 
and Stay Well. Our goal was to build on the Smiles4Miles Oral Health Promotion model by including an early intervention, Minimal Intervention Dentistry (MID) outreach program.

\section{Region}

Barwon Health and Colac Area Health provide oral health services to the Colac-Otway Shire (population 20,345: area 3,433 $\mathrm{km}^{2}$ ) and Greater Geelong (population 221,515: area 1,247 $\mathrm{km}^{2}$ ) in South-West Victoria, Australia (Figure 1). People living in the region may have to travel $100 \mathrm{~km}$ to attend a public or private dental clinic. The area includes regional towns, small townships, coastal resort towns, small acreage properties and larger farms.

\section{Methods}

In 2013, initial contact in Geelong was made with early learning centres/Kindergartens (children aged 3-5 years), under the administration of the Geelong Kindergarten Association (GKA) and six independently run centres. These Kindergartens were involved in the Smiles4Miles program and had in place the framework and policies to support a health program. The new program introducing the MID approach to Kindergartens was titled Kinder Wide Smiles. Within the Colac-Otway region, all Kindergartens had been involved in the Smiles4Miles program as this region held fewer centres with no governing organisation.

Oral Health Therapists (OHTs) made contact with the Director of the Kindergarten and supplied an initial set-up pack to answer any questions. OHTs were present at drop-off and pick-up times for the children, so that parents could become familiar and aware of the new program. Parents filled out consent forms for their child to participate.

Over the course of the year, each Kindergarten was visited three times (Figure 2). A dental chart was created for individual patients that allowed all screening information to be recorded on the same sheet over the three visits annually. Patient information was entered into the Dental Health Services Victoria Titanium clinical record and a Barwon Health Access database for research purposes.

A dental kit was used at each visit and included; fluoride varnish, micro brushes, cotton roll, gauze, gloves, glasses, mirrors, rubbish bags, antiseptic hand scrub and head-torch. Every child was supplied with a toothbrush and toothpaste, irrespective of consent being given to participate in the program. OHTs, Dentists and Dental Assistants participated in the program. At each visit, a communal place would be chosen for dental examinations so children did not feel that they were being separated from the main group. The locations were private enough that children would not get distracted by other activities occurring in the room. A small table and two chairs were often used. The Kindergarten teacher would bring the children to the screening area. Three forms of identification included the name of child, date of birth and gender and consent for screening and fluoride application were checked before proceeding with the dental examination.

Over the last decade the International Caries Detection and Assessment System (ICDAS) has been introduced to measure the surface changes and potential depth of carious lesions using surface characteristics [14]. The ICDAS method includes identifying the progression of early enamel carious lesions and obvious dentine carious lesions. Scoring of not sealed or restored surfaces includes: 00 Sound tooth surface; 01 First visual change in enamel; 02 Distinct visual change in enamel; 03 Enamel breakdown, no dentine visible; 04 Underlying dark shadow from dentine, with or without localised enamel breakdown; 05 Distinct cavity with visible dentine and 06 Extensive distinct cavity with visible dentine. Fillings or crowns were recorded along with sealed surfaces and hypomineralization. If a hypomineralized surface showed signs of caries, the scoring for the caries took precedence in the scoring system.

All clinicians involved with the Kinder Wide Smiles project undertook an ICDAS training program. Over 50 images ranging from ICDAS scores 0-6 were used to assess all clinicians within the group and promote discussion between difficult cases. Clinicians were calibrated in a closed group environment to ensure consistency amongst the group. Each child participating in the study had ICDAS scores recorded for each tooth surface.

\section{Visit 1 and Visit 3}

Children whose parents had consented to the program were screened for early signs of decay using the ICDAS system $(0=$ sound surface to $6=$ extensive cavity with visible dentine). The clinician would score each surface with the dental assistant recording the information on the child's chart. Fluoride application $(0.25 \mathrm{ml} /$ tooth $)$ with Duraphat (Colgate-Palmolive Pty Ltd ${ }^{\circ}$ ) was applied to white spot lesions or decay with an ICDAS score greater than 0 if consent had been given from a parent. The presence of plaque was recorded by scoring sextants of the mouth (posterior and anterior teeth) with a 0 (no plaque) or 1 (plaque evident). Each child was questioned about teeth brushing habits and the process took approximately 3-6 minutes per child.

Parents were given a report of the visit that noted that no treatment was required; or white-spot lesions were identified and Duraphat applied; or your child refused screening. If advanced decay (ICDAS score of $3+$ ) was detected, a referral was sent home with the child to alert the parent of their child's need for further treatment. Upon returning to the dental clinic, all data was entered into the clinical record. An "intervention" form was completed for each visit outlining the Kindergarten details, number of children screened, and any events that occurred at the Kindergarten.

\section{Visit 2}

In addition to screening the children's teeth, a parent engagement session was conducted. Information about baby teeth, diet, tooth brushing and flossing, early-signs of decay, and treatment options were covered in this presentation. Parental engagement included any

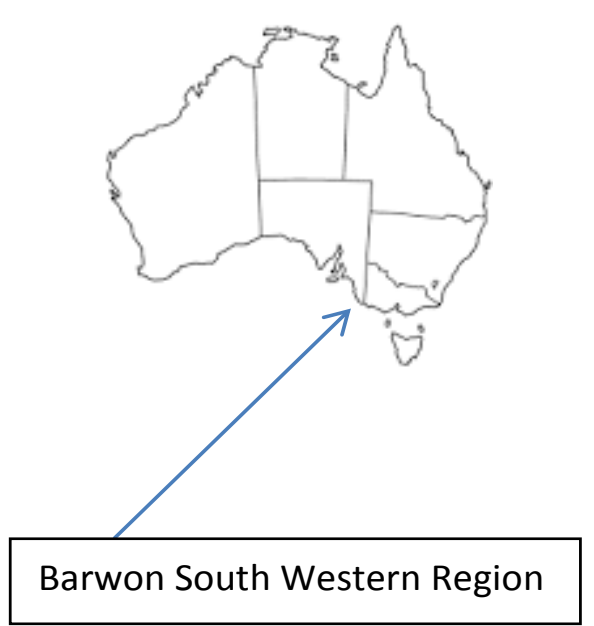

Figure 1: Study region: Geelong and Colac, South-West Victoria, Australia. 


\section{Kinder Wide Smiles Flow Chart}

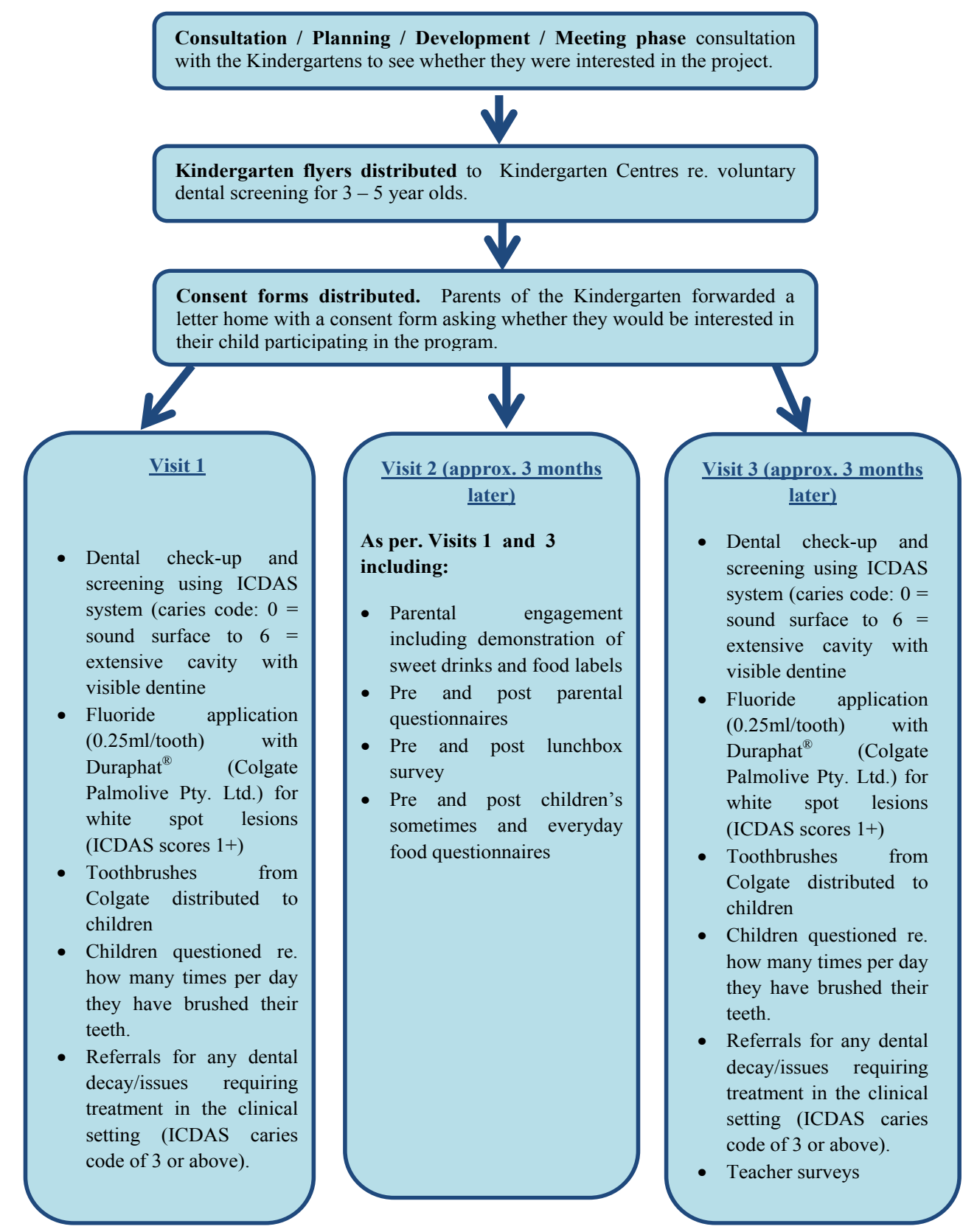

Figure 2: Kinder wide smiles flow chart of visits to kindergartens.

general questions about their children's dental health or the program. A questionnaire explored the success of these sessions on parent's dental knowledge. A 'sometimes and everyday' food game engaged children and parents alike to identify healthy food choices.

The program was continued at Kindergartens in 2014 and extended to include children in the first year of primary school (5-6yr).

\section{Results}

\section{Kindergartens}

In 2013, fifty-eight Kindergartens in the Geelong (44) and Colac-
Otway (14) region participated in the Kinder Wide Smiles program. Dental examinations were attended by 2,320 children, representing $66 \%$ of children enrolled at these settings. At Visit 1 there were 1,989 children, 1,949 attended Visit 2 and 1,965 children attended Visit 3 (Figure 3). Duraphat was applied to tooth surfaces with an ICDAS score of 01,02 or 03 . Fluoride varnish was applied for 723 (36\%), 810 (42\%) and 917 (47\%) children at Visits 1, 2 and 3, respectively. Fluoride was applied on at least one visit for 1,253 (54\%) children. Two hundred and thirty-nine (12\%) referrals were made at the initial visit. At the second visit, 141 who were referred at the first visit were referred once again for dental appointments and a further 138 (9\%) children were 


\section{Kindergarten children (3-5yrs)}

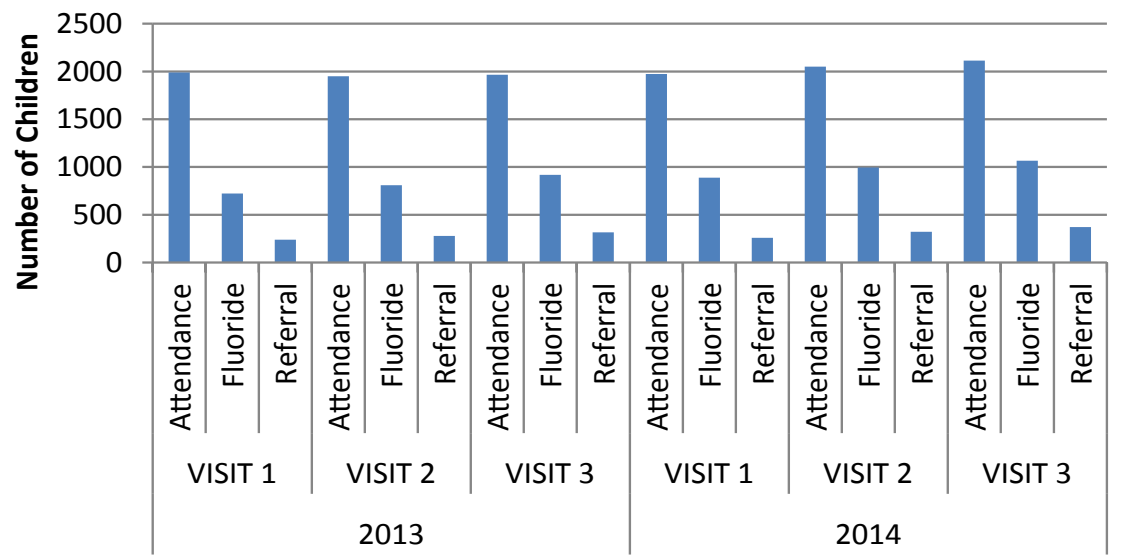

Figure 3: Number of children attending dental visits at the Kindergarten and those with fluoride applied, referred for further dental procedures and number that attended these referrals.

\begin{tabular}{|c|c|c|c|c|}
\hline \multirow[b]{2}{*}{ Visit 1} & \multicolumn{4}{|c|}{ - The Index of Relative Socio-Economic Advantage and Disadvantage (IRSAD) } \\
\hline & Lowest Tertile $n=495$ & Middle Tertile $n=324$ & Upper Tertile $n=1,183$ & $\mathrm{p}$ value \\
\hline $\begin{array}{l}\text { Number of children with at least one } \\
01 \text { surface }\end{array}$ & $32(6.5 \%)$ & $10(3.1 \%)$ & $62(5.2 \%)$ & 0.10 \\
\hline 02 surface & $227(45.9 \%)$ & $109(33.6 \%)$ & $397(33.6 \%)$ & $<0.01$ \\
\hline 03 surface & $70(14.1 \%)$ & $29(9.0 \%)$ & $68(5.7 \%)$ & $<0.01$ \\
\hline 04 surface & $61(12.3 \%)$ & $18(5.6 \%)$ & $41(3.5 \%)$ & $<0.01$ \\
\hline 05 surface & $62(12.5 \%)$ & $24(7.4 \%)$ & $43(3.6 \%)$ & $<0.01$ \\
\hline 06 surface & $22(4.4 \%)$ & $9(2.8 \%)$ & $13(1.1 \%)$ & $<0.01$ \\
\hline Fluoride applied & $262(52.9 \%)$ & $116(35.8 \%)$ & $510(43.1 \%)$ & $<0.01$ \\
\hline Referral for further dental procedures & $103(20.8 \%)$ & $42(13.0 \%)$ & $113(9.6 \%)$ & $<0.01$ \\
\hline
\end{tabular}

Table 1: Comparison of tooth surfaces for children attending Kindergartens in postcodes linked to the lowest, middle and upper tertile of Index of Relative Socio-Economic Advantage and Disadvantage (IRSAD) for he Kindergartens in 2014.

referred for the first time. At the final visit for the year, 35 new referrals were scheduled and 281 children referred once again from visit 1 or 2 .

At Visit 1 in 2013 there was 1,989 children screened with 1,189 (60\%) presenting with no signs of decay. Of the remaining $40 \%, 631$ children (32\%) had at least one surface with an ICDAS of 01 or 02 and potentially reversible. Fluoride was applied to these surfaces. In total there was 565 surfaces scored 01 and 1,359 surfaces scored 02. At Visit $2,68 \%$ of these surfaces with initial signs of decay remained stable or improved. At Visit 3, 66\% of surfaces remained stable.

In 2014, the program continued for Kindergartens in the region with 2,580 participating and the participation rate increased to $71 \%$. Fluoride was applied to 888 (45\%), 995 (49\%) and 1,066 (41\%) children for Visit 1, 2, and 3, respectively (Figure 3). Referral for dental appointments occurred for $258(13 \%), 322(16 \%)$ and $371(18 \%)$ of the Kindergarten children.

Kindergartens were grouped into tertiles of the The Index of Relative Socio-Economic Advantage and Disadvantage (IRSAD) scale according to postcode and tooth surfaces for the children compared for signs of decay. This assignment makes the assumption that all children attending a specific Kindergarten comes from a family with a background such that their individual socioeconomic status is defined by the area-level socio-economic status in which the Kindergarten is located. Table 1 showed that there was an obvious increase in decay for children attending Kindergartens in the more disadvantaged areas of the region in 2014, by as much as $10 \%$ for referrals for dental procedures.

\section{Primary schools}

In 2014 , the program continued for the first time in the initial year of Primary School with 741 children assessed in 25 schools. Fluoride was applied to 384 (59\%), 386 (59\%) and 421 (66\%) children for Visit 1,2 , and 3, respectively (Figure 4). Referral for dental appointments occurred for 198 (30\%), 206 (31\%) and 245 (39\%) of the Primary School children.

Tooth surfaces for children screened at both Kindergarten in 2013 and Primary School in 2014 (KPS: $\mathrm{n}=336$ ) were compared to children assessed for the first time at Primary School in 2014 (PS: $n=405$ ) (Table 2). A higher proportion of PS children having their $1^{\text {st }}$ visit demonstrated early signs of decay (ICDAS 01) (PS vs. KPS: $9.7 \%$ vs. $5.8 \%, \mathrm{p}=0.06$ ) and advanced decay (ICDAS 03-06) (PS vs. KPS: $38.9 \%$ vs. $32.7 \%, \mathrm{p}=0.10$ ) for at least one tooth surface (Table 1). Referrals for further treatment were significantly higher for the PS children (PS vs. KPS: $34 \%$ vs. $26 \%, p=0.04)$.

\section{Discussion}

The Kinder Wide Smiles program successfully intervened in the oral health of 5,305 children in the region. The Minimal Intervention Dentistry (MID) approach to dentistry has been used to stabilize early lesions and to enhance primary prevention. Kinder Wide Smiles 


\section{Primary School Children (age 5-6yr)}

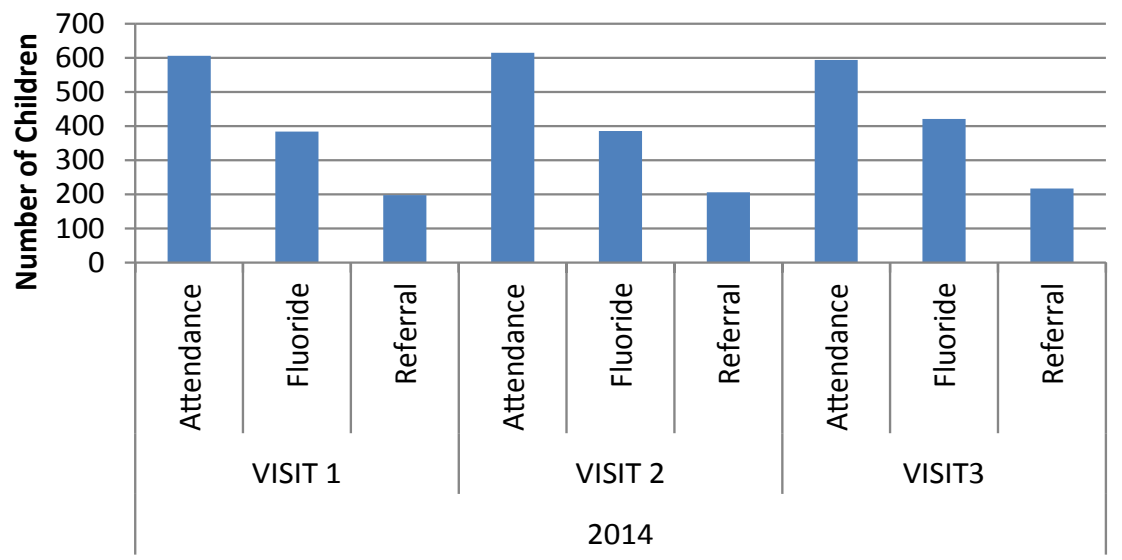

Figure 4: Number of children attending visits at Primary School and those with fluoride applied, referred for further dental procedures and number that attended these referral appointments.

\begin{tabular}{|c|c|c|}
\hline & \multicolumn{2}{|c|}{2 years of screening compared to 1 year of screening } \\
\hline $\begin{array}{c}\text { Visit 1. 2014 } \\
\text { at Primary School }\end{array}$ & $\begin{array}{c}\text { Screened at Primary School (2014) and } \\
\text { Kindergarten }(2013) \\
n=294\end{array}$ & $\begin{array}{c}\text { Screened at Primary School only (2014) } \\
n=360\end{array}$ \\
\hline $\begin{array}{c}\text { Number of children with at least one } \\
\text { 01 surface }\end{array}$ & $17(5.8 \%)$ & $35(9.7 \%)$ \\
\hline 02 surface & $131(44.6 \%)$ & $172(47.8 \%)$ \\
\hline 03 surface & $49(16.7 \%)$ & $76(21.1 \%)$ \\
\hline 04 surface & $51(17.3 \%)$ & $68(18.9 \%)$ \\
\hline 05 surface & $31(10.5 \%)$ & $64(17.8 \%)$ \\
\hline 06 surface & $23(7.8 \%)$ & 0.41 \\
\hline Fluoride applied & $159(54 \%)$ & 0.15 \\
\hline Referral for further dental procedures & $77(26 \%)$ & $225(63 \%)$ \\
\hline
\end{tabular}

Table 2: Comparison of tooth surfaces for children screened at both Kindergarten in 2013 and Primary School in 2014 to those only screened at Primary School in 2014

includes the administration of Duraphat (fluoride) which has been efficacious in reducing the incidence of early childhood caries. Most importantly, one of the barriers for children not presenting to static dental clinics has been eliminated. Parents, guardians and Kindergarten children were actively supported to take responsibility for their oral health care.

The education process provided easily accessible information at hand for the guardians and children alike. Parents reported their children seen during the program "to be confident and less anxious about their dental experience, even encouraging the less confident children: a good first step before children are exposed to the dental clinic setting". Teachers reported the program as "valuable for introducing children to the dentist in a non-threatening setting and there was no real interruption to classes. Children look forward to the visits".

This current study reports on a program that is an innovative approach to service delivery and health care utilising the 'Right Time, Right Place, Right Care' (R3 principles). Kinder Wide Smiles demonstrates an innovative approach to public dental care by taking the professional team to the community and only children with caries are referred to the clinics for treatment (usually fillings and extractions). Previous reviews [15-17] have reported that fluoride varnishes are a useful tool in caries prevention in young people. In order to improve the access to dental care, two mobile dental clinics have been purchased. The mobile dental clinic will service communities in the region that do not have access to public or private dentistry and will accept referrals from those children identified at Kindergarten screenings. Early results demonstrate that this program represents a significant improvement when comparing 'outreach' funding vs 'in-clinic' funding. The value per course of care for Kinder Wide Smiles for Barwon Health and Colac Area Health is significantly less than the 'in-clinic' costs. Examinations and fluoride application takes only 3-6 minutes for each child, compared with the usual 30 minute appointments in dental clinics. The Kinder Wide Smiles project is a holistic project which also includes oral health education.

\section{Ethics}

This study was reviewed by the Barwon Health Research Office (Research Project Number 14/07) and was carried out according to the National Statement on Ethical Conduct in Human Research 2007 (updated in 2014) and local research policies and guidelines.

\section{References}

1. Marcenes W, Kassebaum NJ, Bernabé E, Flaxman A, Naghavi M, et al. (2013) Global burden of oral conditions in 1990-2010: a systematic analysis. J Dent Res 92: 592-597.

2. Petersen PE, Bourgeois D, Ogawa H, Estupinan-Day S, Ndiaye C (2005) The global burden of oral diseases and risks to oral health. Bull World Health Organ 83: 661-669.

3. Chrisopolous S, Beckwith K, Harford J (2011) Oral health and dental care in Australia: Key facts and figures. Cat no. DEN214, Australian Institute of Health and Welfare, Canberra, Australia. 
Citation: Mason A, Mayze L, Pawlak J, Henry MJ, Sharp S, et al. (2015) A Preventative Approach to Oral Health for Children in a Regional/Rural Community in South-West Victoria, Australia. Dentistry 5: 313. doi:10.4172/2161-1122.1000313

4. Thomson WM, Malden PE (2011) Assessing change in the family impact of caries in young children after treatment under general anaesthesia. Acta Odontol Scand 69: 257-262.

5. Marshall TA, Eichenberger-Gilmore JM, Broffitt BA, Warren JJ, Levy SM (2007) Dental caries and childhood obesity: roles of diet and socioeconomic status. Community Dent Oral Epidemiol 35: 449-458.

6. Zander A, Sivaneswaran S, Skinner J, Byun R, Jalaludin B (2013) Risk factors for dental caries in small rural and regional Australian communities. Rural Remote Health 13: 2492

7. http://www.aihw.gov.au/publication-detail/?id=60129548265

8. Pawlak JA, Calache H, de Silva AM, Henry MJ, Smith M (2015) Audit of Gross Decay Treatment in Young Children under General Anaesthetic. Dentistry 5: 302.

9. Verco S, Bajurnow A, Grubor D, Chandu A (2011) A five-year assessment of clinical incidents requiring transfer in a dental hospital day surgery unit. Aust Dent J 56: 412-416.

10. Frencken JE, Peters MC, Manton DJ, Leal SC, Gordan VV, et al. (2012) Minimal intervention dentistry for managing dental caries - a review: report of a FDI task group. Int Dent J 62: 223-243.

11. Haynes S (2013) A perspective from the dental industry on minimum intervention dentistry. Aust Dent J 58 Suppl 1: 66-69.
12. Calache H1, Hopcraft MS, Martin JM (2013) Minimum intervention dentistry--a new horizon in public oral health care. Aust Dent J 58 Suppl 1: 17-25.

13. Slade GD, Bailie RS, Roberts-Thomson K, Leach AJ, Raye I, et al. (2011) Effect of health promotion and fluoride varnish on dental caries among Australian Aboriginal children: results from a community-randomized controlled trial. Community Dent and Oral Epidemiol 39: 29-43.

14. International Caries Detection and Assessment System (ICDAS) Coordinating Committee 2005. Rationale and evidence for the international caries detection and assessment system (ICDAS II): International Caries Detection and Assessment System (ICDASII Workshop) Baltimore, Md, USA.

15. Strohmenger L, Brambilla $E$ (2001) The use of fluoride varnishes in the prevention of dental caries: a short review. Oral Dis 7: 71-80.

16. Marinho VCC, Worthington HV, Walsh T, Clarkson JE (2013) Fluoride varnishes for preventing dental caries in children and adolescents. Cochrane Oral Health Group.

17. Mohammadi TM, Hajizamani A, Hajizamani HR, Abolghasemi B (2015) Fluoride varnish effect on preventing dental caries in a sample of 3-6 years old children. J Int Oral Health 7: 30-35. 